\title{
Pengaruh Model Pembelajaran TGT dengan Media Pop Up Terhadap Hasil Belajar Kelas IV Tema 6 Cita-Citaku Subtema 3
}

\author{
Ririn Rusmiati ${ }^{1}$, Ary Susatyo Nugroho ${ }^{2}$ \\ ${ }^{1,2}$ Pendidikan Guru Sekolah Dasar, Fakultas IImu Pendidikan,Universitas PGRI Semarang \\ Ririnrusmiati24@gmail.com
}

\begin{abstract}
Abstrak
Peneliti ini bertujuan untuk mengetahui adanya pengaruh untuk meningkatkan hasil belajar tema 6 subtema 3 atau tidaknya model pembelajaran TGT dengan media Pop Up . Penelitian ini merupakan penelitian True Experimental Design jenis kuantitatif. Penelitian ini menggunakan Posttest-only Control Design. Populasi dalam penelitian ini adalah seluruh peserta didik kelas IVA dan IVB SD Kusuma Bhakti Semarang berjumlah 35 siswa tahun ajaran 2018/2019. Intrumen yang digunakan adalah wawancara, dokumentasi dan tes. Analisis Data menggunakan Teknis analisis data peneliti menggunakan uji normalitas dan uji himogenitas, (uji-t). Uji normalitas digunakan untuk mengetahui kelas tersebut berdistribusi normal atau tidak. Uji homogenitas digunakan untuk mengetahui apakah varians homogen apa tidaknya. Uji t-test digunakan untuk mengetahui perbedaan hasil belajar. Hasil penelitian yang dilakukan dapat disimpulkan bahwa model pembelajaran Hasil penelitian dapat disimpulkan bahwa model pemeblajaran TGT dengan media Pop Up dapat meningkatkan hasil belajar siswa kelas IV tema 6 subtema 3 pembelajaran 1-3. Hal ini dapat dilihat Hal tersebut dilihat dari hasil perhitungan uji- $t$ dengan taraf signifikan $=5 \%$ Dengan menggunakan uji-t dua pihak didapatkan nilai sebesar $^{T_{\text {hitung }}} 3,038$ denga $^{n} \quad T_{\text {tabel }}=1,995$ Karena $T_{\text {tabel }}>T_{\text {hitung }}$ yaitu 1,995>3,038 Dengan demikian ${ }^{H_{0}}$ ditolak dan $H_{\varpi}$ diterima. Artinya ada perbedaan hasil belajar antara pembelajaran yang menggunakan model pembelajaran TGT dengan media Pop Up dengan model pembelajaran konvensional pada tema 6 subtema 3 pembelajaran 1-3.
\end{abstract}

Kata Kunci: Peningkatan Kinerja Guru Produktif, Pembinaan Kompetensi Profesional

\begin{abstract}
This researcher aims to determine the effect of improving the learning outcomes of theme 6 sub-theme 3 or not the TGT learning model with Pop Up media. This research is a quantitative type of True Experimental Design. This study uses Posttest-only Control Design. The population in this study were all IVA and IVB grade students of SD Kusuma Bhakti Semarang totaling 35 students in the 2018/2019 academic year. The instruments used were interviews, documentation, and tests. Data Analysis using Technical data analysis researchers used the normality test and homogeneity test, (t-test). The normality test is used to find out whether the class is normally distributed or not. The homogeneity test is used to determine whether or not homogeneous variance is. The t-test test is used to determine differences in learning outcomes. The results of the research can be concluded that the learning model The results of the study can be concluded that the TGT learning model with Pop Up media can improve the learning outcomes of students in class IV theme 6 sub-theme 3 learning 1-3. This can be seen from the results of the t-test calculation with a significant level of $5 \%$. Using the two-party $t$-test the value is $T_{-}$count3.038 with $\llbracket T \rrbracket$ _ (table) $=1.995$ Because $T_{-}$table> $T_{\text {_count is }} 1.995>3.038$ Thus $H_{-}(0)$ is rejected and $H_{-} a$ is accepted. This means that there are differences in learning outcomes between learning using the TGT learning model and Pop Up media with conventional learning models in theme 6 sub-themes 3 learning 1-3.
\end{abstract}

Keywords: Increasing the performance of productive teachers, fostering professional competence 


\section{Pendahuluan}

Pendidikan merupakan suatu yang sangat penting dewasa ini. Hampir semua orang mengenyam pendidikan dari tingkat pendidikan dasar hingga berlomba-lomba sampai pada tingkat pendidikan tinggi. Hal tersebut dilakukan untuk menghadapi tantangan zaman sekarang ini maupun dimasa depan. Sebagaimana yang didefinisikan dalam Undang-Undang No. 20 Tahun 2003 pasal 1 tentang Sistem Pendidikan Nasional menyebutkan bahwa pendidikan adalah usaha sadar dan terencana untuk mewujudkan suasana belajar dan proses pembelajaran agar peserta didik secara aktif mengembangkan potensi dirinya untuk memiliki kekuatan spiritual keagamaan, pengendalian diri, kepribadian, kecerdasan, akhlak mulia, serta keterampilan yang diperlukan dirinya, masyarakat, bangsa dan negara.

Pelaksanaan pendidikan di Indonesia diatur suatu kurikulum. Undang-Undang Nomor 20 Tahun 2003 tentang Sistem Pendidikan Nasional menyebutkan bahwa kurikulum adalah seperangkat rencana dan pengaturan mengenai tujuan, isi, dan bahan pelajaran serta cara yang digunakan sebagai pedoman penyelenggaraan kegiatan pembelajaran untuk mencapai tujuan pendidikan tertentu.Berdasarkan Peraturan Menteri Pendidikan dan Kebudayaan Nomor 67 Tahun 2013 tentang kerangka dasar dan struktur kurikulum Sekolah Dasar/Madrasah menyebutkan bahwa Kurikulum 2013 dikembangkan dengan teori pendidikan berdasarkan standar dan kurikulum berbasis kompetensi. Struktur Kurikulum 2013 dikembangkan menjadi empat kompetensi inti yaitu KI 1 (sikap spiritual), KI 2 (sikap sosial), KI 3 (pengetahuan), dan KI 4 (keterampilan). Berdasarkan kompetensi inti disusun mata pelajaran dan alokasi waktu yang sesuai dengan karakteristik satuan pendidikan.

Pada proses implementasi kurikulum 2013 dimana dalam pelaksanaan pembelajaran kurikulum siswa harus menjadi aktif seperti halnya dalam Peraturan Menteri Pendidikan dan Kebudayaan Nomor 65 Tahun 2013 tentang Standar Proses Pendidikan Dasar dan Menengah Proses Pembelajaran pada satuan pendidikan diselenggarakan secara interaktif, inspiratif, menyenangkan, menantang, memotivasi peserta didik untuk berpartisipasi aktif, serta memberikan ruang yang cukup bagi prakarsa, kreativitas, dan kemandirian sesuai dengan bakat, minat, dan perkembangan fisik serta psikologis peserta didik. Untuk itu setiap satuan pendidikan melakukan perencanaan pembelajaran, pelaksanaan proses pembelajaran serta penilaian proses pembelajaran untuk meningkatkan efisiensi dan efektivitas ketercapaian kompetensi lulusan.

Pembelajaran Kurikulum 2013 pada jenjang Sekolah Dasar menggunakan pembelajaran tematik. Menurut Daryanto (2014:3) pembelajaran tematik diartikan sebagai pembelajaran yang menggunakan tema untuk mengaikan beberapa mata pelajaran sehingga dapat memberikan pengalaman bermakna kepada siswa. Salah satu pembelajaran tema di kelas IV yaitu tema 6 yaitu Cita-Citaku.Tema 6 Cita-citaku memuat 3 subtema salah satunya subtema 3 Giat Berusaha Meraih Cita-cita terdapat 6 pembelajaran. Tiga diantarnya yaitu Pembelajaran 1 memuat mata pelajaran Bahasa Indonesia dan IPA sedangkan pembelajaran 2 memuat mata pelajaran Bahasa Indonesia, SBdP dan IPA. Pembelajaran 3 yaitu Bahasa Indonesia, PPKn dan IPS.

Hasil wawancara dengan guru kelas IV SD Kusuma Bhakti Ibu Megawati Kusuma Dewi , S.Pd . Adakalanya guru menggunakan model pembelajaran dan tidak menggunakan model pembelajaran. Guru didominasi dengan menggunakan model konvensional sehingga kurang menarik perhatian siswa. Permasalahan tersebut menyebabkan hasil belajar yang diperoleh siswa masih rendah yakni di bawah KKM 70. Tabel dibawah menujukkan data nilai ulangan harian siswa tema 1 yang menunjukkan bahwa masih ada siswa yang nilainya masih dibawah KKM. Kelas IV A dari 35 siswa yang memenuhi KKM hanya 12 anak, sedangkan kelas IV B dari 35 siswa yang memenuhi KKM hanya 10 anak. Data nilai ulangan harian siswa tema 1 dapat disajikan pada Tabel 1.

Tabel 1 Data Nilai Ulangan Harian Siswa Tema 1

\begin{tabular}{cccc}
\hline Kelas & Jumlah Siswa & Tuntas & Tidak Tuntas \\
\hline IVA & 35 & 12 Anak & 23 Anak \\
IVB & 35 & 10 Anak & 25 Anak \\
\hline
\end{tabular}

Upaya menangani permasalahan di atas adalah dengan model pembelajaran dan media pembelajaran. Media dan model pembelajaran yang dapat digunakan yaitudengan menggunakan model pembelajaran Team, Game Tournamen (TGT) . Model pembelajaran 
TGT dapat diterapkan di sekolah dasar, karena model ini menekankan pada partisipasi dan aktivitas siswa yang mengandung unsur game dan turnamen sehingga siswa tidak merasa bosan. Menurut Hamdani (2011:92) pembelajaran kooperatif model TGT adalah salah satu tipe atau model pembelajaran kooperatif yang mudah diterapkan, melibatkan aktivitas seluruh siswa tanpa ada perbedaan status, melibatkan peran siswa sebagai tutor sebaya, mengandung unsur permainan dan reinforcement. Sedangkan media yang dapat menengani masalah tersebut yaitu media Pop Up. Menurut Okamura Pop Up adalah selembar kertas yang dilipat dan struktur tiga dimensi yang muncul ketika dibuka (Nugraheni, 2015:37). Selain itu pop up book dianggap mempunyai daya tarik tersendiri bagi anak-anak karena disajikan dengan visualisasi yang dapat dibentuk-bentuk yang dibuat dengan melipat dan sebagainya (Khoirotun dkk, 2014:2). Selain itu pop up book dianggap mempunyai daya tarik tersendiri bagi anak-anak karena disajikan dengan visualisasi yang dapat dibentuk-bentuk yang dibuat dengan melipat dan sebagainya. Peneliti memilih media Pop up book karena didalam materi tema 6 Subtema 3 kelas IV didominasi dengan gambar sehingga peneliti memilih media pop up book sebagai media yang digunakan dalam penelitian.

Menurut Diah (2018) mengatakan bahwa Media pembelajaran Pop-Up Book dinyatakan valid dan dapat digunakan untuk peserta didik dalam kegiatan belajar untuk meningkatkan hasil belajar. Hal tersebut terbukti dengan hasil dari uji ahli dan uji coba siswa berikut,Pada uji coba kelompok kecil mendapatkan hasil dengan kriteria sangat baik, dan pada uji coba lapangan mendapatkan hasil dengan kriteria sangat baik.

Hal ini di dukung juga oleh Khoiriyah (2018) yang menyatakan bahwa tingkat kelayakan produk oleh ahli materi dan ahli media termasuk dalam kategori valid dan layak digunakan namun perlu direvisi. Dari hasil data keterterapan media menunjukkan hasil media pembelajaran Pop-Up Book valid dan layak diterapkan pada pembelajaran.

Berdasarkan hasil penelitian dan pengembangan yang telah dilakukan Safri (2017), maka disimpulkan bahwa media belajar pop-up book yang telah dikembangkan melalui model ADDIE, melalui tahapan analisis, desain, pengembangan, implementasi dan evaluasi dengan persentase kelayakan rata-rata dari 5 validator sebesar 92,67. Hal ini menunjukan bahwa media belajar pop-up book sangat layak digunakan sebagai media pembelajaran.

Model pembelajaran TGT dapat berpengaruh untuk meningkatkan hasil belajar siswa. Hal ini dapat dilihat dari penelitian yang telah dilakukan oleh Nur Azizah, dkk ( 2018) tentang "Pengaruh Model Tgt Berbantu Media Utama Terhadap Hasil Belajar Matematika Ditinjau Dari Aktivitas Belajar Siswa Kelas V SDN 01 Wonotirto". Hasil penelitian menyatakan bahwa terdapat pengaruh yang signifikan model teams games tournament terhadap hasil belajar matematika kelas $\mathrm{V}$. Hal ini dapat dilihat pada anasis uji hipotesis untuk menguji ada atau tidaknya pengaruh model TGT terhadap hasil belajar siswa matematika kelas $\mathrm{V}$ diperoleh $t_{\text {hitung }}=7,406$ dan $t_{\text {tabel }}=1,721$ taraf signifikan $\alpha=5 \%$ dengan $\mathrm{db}=21$, sehingga

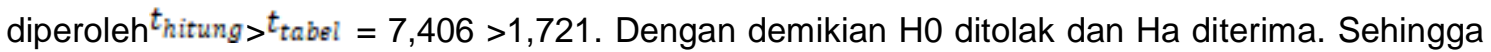
kesimpulannya bahwa hasil belajar matematika siswa kelas V SDN 01 Wonotirto tuntas. Dapat disimpulkan bahwa model Team Game Tournament berbantu media utama terhadap hasil belajar matematika ditinjau dari aktivitas belajar siswa kelas V SDN 01 Wonotirto.

Berdasarkan Uraian di atas, maka peneliti tertarik untuk melakukan penelitian tentangPengaruh Model Pembelajaran TGT Dengan Media Pop Up Terhadap Hasil Belajar Kelas IV Tema 6 Cita-Citaku Subtema 3 SD Kusuma Bhakti Semarang.

Berdasarkan latar belakang masalah yang telah dikemukakan diatas, dapat mengidentifikasi masalah sebagai berikut : 1) Metode pembelajaran masih konvensional atau proses pembelajaran masih berpusat oleh guru sehingga siswa kurang aktif dalam kegiatan pembelajaran 2) Rendahnya hasil belajar yang dicapai siswa kelas IV masih ada yang dibawah KKM 70.

Berdasarkan latar belakang dan identifikasi masalah yang ada maka peneliti melakukan pembatasan masalah. adalah Pengaruh model pembelajaran TGT dengan media pop up book terhadap hasil belajar. Peneliti membatasi pada hasil belajar kognitif dengan penggunaan model TGT dengan media pop up book pada Tema 6 Subtema 3 pembelajaran 1-3.

Berdasarkan Identifikasi masalah dan pembatasan masalah di atas, maka dapat dirumuskan masalah sebagai berikut: Berdasarkan pembatasan masalah yang telah dipaparkan maka rumusan masalah pada penelitian ini adalah "Apakah model pembelajaran TGT (team, game, tournamen) dengan media Pop Up Book dapat meningkatkan hasil belajar tema 6 subtema 3 kelas IV SD Kusuma Bhakti tahun ajaran 2018/2019? 
Tujuan dan Manfaat Penelitian ini adalah untuk mengetahui mengetahui adanya pengaruh untuk meningkatkan hasil belajar tema 6 subtema 3 atau tidaknya model pembelajaran

\section{Metode}

Metode yang digunakan dalam penelitian ini yaitu True Experimental Design, peneliti dapat mengontrol semua variabel luar yang mempengaruhi jalannya eksperimen. Dengan demikian validitas internal (kaualitas pelaksanaan rancangan penelitian) dapat menjadi tinggi. Ciri utama penelitian true experimental design adalah bahwa, sampel yang digunakan untuk eksperimen maupun sebagai kelompok kontrol diambil secara random dari populasi tertentu. Jadi cirinya adalah adanya kelompok kontrol dan sampel dipilih secara random. Menurut Sugiyono (2017:112) Posttest-Only Control Design dipilih secara random (R). Kelompok pertama diberi perlakuan $(X)$ dan kelompok yang lain tidak. Kelompok yang diberi perlakuan disebut kelompok eksperimen dan kelompok yang tidak diberi perlakuan disebut kelompok kontrol. Pengaruh adanya perlakuan (treatment) adalah $\left(O_{1}: O_{2}\right)$

Dalam penelitian kelompok eksperimen akan diberikan treatmen atau perlakuan, yaitu dengan menggunakan model TGT (Teams, Games, Tournement) dengan media Pop Up, sedangkan kelompok kontrol merupakan kelompok yang tidak diberi perlakuan. Bentuk Posttest only control design adalah sebagai berikut:

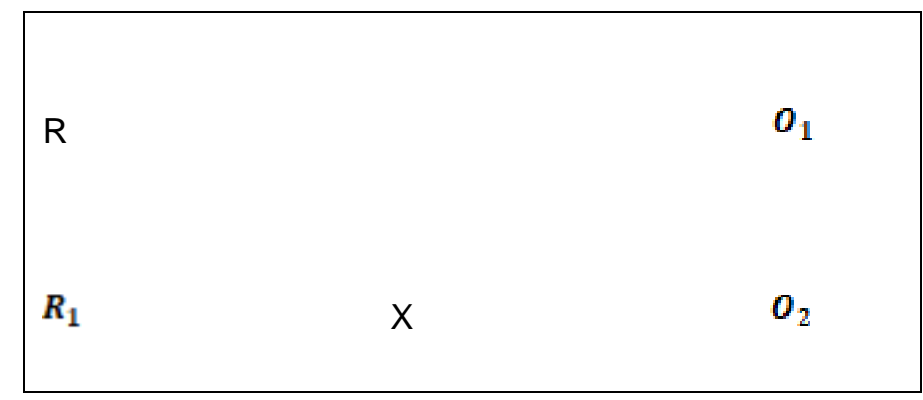

Gambar 1. Desain Penelitian

Keterangan

$\mathbf{R}=$ Kelas kontrol dipilih secara cluster random sampling

$\boldsymbol{R}_{1}=$ Kelas eksperimen dipilih secara cluster rondom sampling

$\boldsymbol{X}=$ Perlakuan (treatmen)

$\boldsymbol{O}_{1}=$ Hasil posttest pada kelas kontrol

$\mathrm{O}_{2}=$ Hasil posttest pada kelas eksperimen

Berdasarkan design ini, terdapat dua kelompok yang memiliki kemampuan yang sama, kemudian untuk mengetahui keadaan awal adalah perbedaan antara kelas kontrol dan kelas eksperimen digunakan dangan cluster random. Selanjutnya dari kelas eksperimen diberi perlakuan dengan menggunakan model TGT dengan media Pop Up tetapi kelas kontrol tidak diberi perlakuan, tetapi hanya menggunakan metode ceramah. Hasil posttest yang baik bila nilai kelas eksperimen berbeda sangat signifikan. Pengaruh perlakuan adalah $\left(O_{1}: O_{2}\right)$. Jenis penelitian yang digunakan dalam penelitian ini adalah penelitian kuantitatif dalam bentuk True Experimental Design dengan Posstest-Only Control Design. Rancangan penelitian yang digunakan pada penelitian ini disajikan sebagai berikut:

Tabel 2. Perlakuan

\begin{tabular}{clc}
\hline Kelompok & \multicolumn{1}{c}{ Perlakuan } & Tes \\
\hline Eksperimen & $\begin{array}{l}\text { Pembelajaran dengan model TGT (Teams, Games, Tournament) } \\
\text { dengan media Pop Up }\end{array}$ & post-test \\
\hline Kontrol & $\begin{array}{l}\text { Pembelajaran yang berpusat pada guru yaitu dengan } \\
\text { menggunakan model ceramah }\end{array}$ & post-test \\
\hline
\end{tabular}


Berdasarkan penelitian yang sesungguhnya pengaruh treatment dianalisis dengan uji beda pakai statistik t-test, jika terdapat perbedaan yang signifikan antara kelompok eksperimen dan kelompok kontrol, maka perlakuan yang diberikan berpengaruh secara signifikan. Peneliti ini bermaksud membandingkan hasil belajar dari dua kelas yang dijadikan penelitian. Untuk membedakan hasil belajar maka kelas eksperimen IVA diberikan perlakuan sesuai model TGT (Teams, Games, Tournament) dengan media Pop Up dan kelas kontrol IVB menggunakan model konvensional.

\section{Hasil dan Pembahasan}

Penelitian dilakukan di Kusuma Bhakti Semarang pada semester genap tahun ajaran 2018/2019 pada dua kelas yaitu kelas IVA dan IVB dengan jumlah siswa 35 orang masingmasing kelas. Dimana kelas IVA sebagai kelas eksperimen dan kelas IVB sebagai kelas kontrol yang menerapkan model pembelajaran Teams, Game, Tournament (TGT)dengan media Pop Up book pada tema 6 subtema 3 pembelajaran 1-3. Penelitian dilaksanakan pada tanggal 8 April- 15 April 2019.

Sebelum dilaksanakan penelitian, penulis melakukan uji coba soal yang dilakukan di SDN Serutsadang. Instrumen dalam penelitian ini berupa soal pilihan ganda sebanyak 30 butir soal yang diujicobakan di kelas IV dengan jumlah siswa sebanyak 20 siswa. Setelah dilaksanakan uji coba, kemudian dilakukan analisis data berupa uji validitas, reliabilitas, tingkat kesukaran dan daya pembeda. Hasil analisis diperoleh 18 soal yang digunakan sebagai soal posttest. Selanjutnya yaitu melengkapi perangkat pembelajaran yang akan digunakan untuk penelitian di kelas IVA dan kelas IVB SD Khusuma Bakti Semarang meliputi RPP, silabus dan media Pop Up book.

Rancangan penelitian yang digunakan yaitu true-experimental design dengan bentuk posttest only control design. Subjek pada penelitian ini adalah kelas IV SD Kusuma Bhakti yang terdiri dari dua kelas yaitu kelas IVA dan IVB. Penelitian ini dilakukan sebanyak 5 kali pertemuan. Penulis melakukan pembelajaran sebanyak 2 kali di kelas kontrol dan 2 kali di kelas eksperimen dan pertemuan terakhir digunakan untuk melaksanakan posttest.Posttestdiadakan untuk mendapatkan data berupa nilai yang digunakan untuk perbandingan hasil belajar antara kelas kontrol dengan kelas eksperimen.Perbandingan hasil belajar digunakan untuk mengetahui model pembelajaran TGT dengan media Pop Up bookberpengaruh meningkatkan pada hasil belajar tema 6 subtema 3 pembelajaran 1-3 atau tidak berpengaruh dengan pembelajaran konvensional yang berpusat pada guru.

Proses pembelajaran di kelas eksperimen diberikan perlakuan dengan menggunakan model pembelajaran TGT dengan media Pop Up book. Pembelajaran dimulai dengan guru memimpin berdoa. Guru melakukan apersepsi dengan cara mengaitkan materi pembelajaran dalam kehidupan sehari-hari dan menjelaskan materi bahasa Dalam pembelajaran pertama, terdapat dua mapel yaitu Bahasa Indonesia dan IPA. Dalam pembelajaran Bahasa Indonesia siswa dikenalkan dengan puisi yang berjudul penjaga alamku. Sedangkan IPA siswa dikenalkan penjelasan tentang sumber daya alam hayati dan sumber daya alam mineral. Dalam pembelajaran kedua, terdapat tiga mata pelajaran yaitu bahasa indonesia, SBdP (Seni budaya dan prakarya), dan IPA dalam pembelajaran Bahasa Indonesia siswa disajikan materi terkait puisi sahabatku seorang pemulung yang Kemudian untuk SBdP (Seni Budaya dan prakarya), dikenalkan dengan karya seni yang disebut dengan kolase, guru menjelaskan apa itu kolase dan memberikan contoh karyakarya kolase. Dalam pembelajaran ketiga, terdapat tiga mata pelajaran yaitu Bahasa Indonesia, PPKn, dan IPS. Dalam pembelajaran Bahasa Indonesia siswa disuruh untuk membuat puisi yang bertema cita-cita. Kemudian untuk mapel PPKn memahamkan kepada siswa tentang manfaat keberagaman karakteristik individu dalam kehidupan sehari-hari. IPS pemanfaatan sumber daya alam untuk kesejahteraan masyarakat dari tingkat kota/kabupaten sampai tingkat provinsi. Siswa dibagi menjadi 5 kelompok yang beranggotakan 7 siswa dalam setiap kelompoknya untuk melakukan percobaan.Pembagian kelompok dilakukan dengan berhitung lalu siswa berkumpul dengan kelompok sesuai dengan nomor yang didapat. Setiap kelompok menjadi 1 tim. Tim tersebut berfungsi untuk melakukan game dan turnamen yang ditandingkan dengan tim lainnya. Setiap tim dapat bekerjasama dengan teman-teman timnya.

Sedangkan pada kelas kontrol terdapat perbedaan cara mengajar namun dengan materi yang sama. Pada kelas kontrol menggunakan pembelajaran konvensional dengan metode ceramah dan penugasan. Guru membuka pelajaran dengan mengucapkan salam dan 
memimpin bedoa. Guru menyampaiakan materi kepada siswa dan kelas kontrol tidak melakukan percobaan.

Model TGT dapat mempengaruhi peningkatan hasil belajar siswa. Langkah-langkah TGT menurut Robert E. Slavin(2005:163) TGT menggunakan turnamen akademik, dan menggunakan kuis-kuis dan sistem skor kemajuan individu, di mana para siswa berlomba sebagai wakil tim mereka dengan anggota tim lain yang kinerja akademik sebelumnya setara mereka. Langkah- langkah pembelajaran TGT Slavin dalam ( Fathurrohman, 2017: 56) yaitu meliputi penyajian kelas, belajar kelompok, games tournament dan penghargaan kelompok.

Model pembelajaran TGT memiliki kelebihan dan kelemahan Setiap model memiliki keunggulan dan kelemahan masing masing, seperti yang diungkapkan Slavin dalam ( Fathurrohman, 2017:60). Keunggulannya sebagai berikut. Para siswa di dalam kelas-kelas yang mengandung TGT memperoleh teman yang secara signifikan lebih banyak dari kelompok rasial mereka daripada siswa yang ada dalam kelas tradisional danm eningkatkan perasaan/persepsi siswa bahwa hasil yang mereka peroleh tergantung dari kinerja dan bukannya pada keberuntungan. Sedangkan kelemahan TGT Sulitnya mengelompokkan siswa yang memiliki kemampuan heterogen dari segi akademis. Kelemahan ini dapat diatasi jika guru yang bertindak sebagai pemegang kendali teliti dalam menentukan pembagian kelompok waktu yang dihabiskan untuk diskusi oleh siswa cukup banyak sehingga melewati waktu yang sudah ditetapkan. Kesulitan ini dapatdiatasi jika guru mampu menguasai kelas secara keseluruhan dan masih adanya siswa berkemampuan tinggi kurang terbiasa dan sulit memberikan penjelasan kepada siswa lainya. Untuk mengatasi kelemahan ini, tugas guru adalah membimbing dengan baik siswa yang memiliki kemampuan akademik tinggi agar dapat dan mampu menularkan penegtahuannya kepada siswa yang lain.

Media Pop Up bookdapat berpengaruh untuk meningkatkan hasil belajar tema 6 subtema 3. Menurut Dzuanda dalam Pramesti (2011: 1) Pop-Up Book adalah sebuah buku yang memiliki bagian yang dapat bergerak atau memiliki unsur 3 dimensi serta memberikan visualisasi cerita yang menarik, mulai dari tampilan gambar yang dapat bergerak ketika halamannya dibuka

Dari penelitian yang dilakukan oleh peneliti sebelumnya mengenai model TGT yang dilakukan oleh Nur Azizah, dkk (2018) tentang "Pengaruh Model TGT Berbantu Media Utama Terhadap Hasil Belajar Matematika Ditinjau Dari Aktivitas Belajar Siswa Kelas V SDN 01 Wonotirto". Hasil penelitian menyatakan bahwa terdapat pengaruh yang signifikan model teams games tournament terhadap hasil belajar matematika kelas V. Hal ini dapat dilihat pada anasis uji hipotesis untuk menguji ada atau tidaknya pengaruh model TGT terhadap hasil belajar siswa matematika kelas $\mathrm{V}$ diperoleh ${ }^{t_{\text {hitung }}}=7,406$ dan ${ }^{t_{\text {tabel }}}=1,721$ taraf signifikan $\alpha=5 \%$ dengan $\mathrm{db}=21$, sehingga diperoleh ${ }^{t_{\text {hitung }}}{ }^{t_{\text {tabel }}}=7,406>1,721$. Dengan demikian HO ditolak dan Ha diterima. Sehingga kesimpulannya bahwa hasil belajar matematika siswa kelas V SDN 01 Wonotirto tuntas. Dapat disimpulkan bahwa model Team Game Tournament berbantu media utama terhadap hasil belajar matematika ditinjau dari aktivitas belajar siswa kelas V SDN 01 Wonotirto sedangkan penelitian yang dilakukan pada tanggal 8-15 April dengan judul penelitian Pengaruh model pembelajaran TGT dengan media Pop Upterhadap hasil belajar kelas IV tema 6 subtema cira-citaku pembelajaran 1-3 SD Kusuma Bhakti Semarang diperoleh hasil $t_{\text {tabel }}$ DK pembilang $(n 1+n 2-2)=68, \alpha=5 \%, 1995$ (dua pihak). Ternyata $t_{\text {hitung }}>t_{\text {tabel, }}$ yaitu 3,038 $>1995$. Dengan demikian ${ }^{H_{0}}$ ditolak dan ${ }^{H_{\varpi}}$ diterima. Jadi model pembelajaran TGT dengan media Pop Up book dapat meningkatkan hasil belajar pada tema 6 subtema 3 pembelajaran 1-3. Hasil yang diperoleh dari kelas eksperimen lebih tinggi dibandingkan dengan kelas kontrol, bisa dilihat dari nilai posttest kelas eksperimendengan rata-rata 75,19 sedangkan pada kelas kontrol rataratanya 64,86 . Hasil penelitian yang dilakukan sebelumnya sama dengan penelitian yang dilakukan oleh penuulis yaitu dapat bepengaruh meningkatkan hasil belajar.

Dari pembahasan di atas dapat disimpulkan bahwa pembelajaran dengan menggunakan model pembelajaran TGT dengan media Pop Up bookdapat meningkatkan hasil belajar siswa dari pada menggunakan metode konvensional.Rata-rata kelas eksperimen lebih tinggi dibandingkan dengan kelas kontrol.Dengan demikian, ada Pengaruh model pembelajaran TGT dengan media Pop Up dapat meningkatkan hasil belajar siswa kelas IV tema 6 cita-citaku subtema 3 SD Kusuma Bhakti Semarang. 


\section{Simpulan dan Saran}

Berdasarkan penelitian yang dilakukan, maka dapat disimpulkan bahwa model pembelajaran TGTdengan media Pop Updapatmeningkatkan hasil belajar siswa kelas IV tema 6 subtema 3 pembelajaran 1-3. Hal tersebut dilihat dari hasil perhitungan uji- $t$ dengan taraf signifikan $=5 \%$ Dengan menggunakan uji-t dua pihak didapatkan nilai sebesar $T_{\text {hitung 3,038 }}$ denga $^{n} \quad T_{\text {tabel }}=1,995$ Karena $T_{\text {tabel }}>T_{\text {hitung }}$ yaitu $1,995>3,038$ Dengan demikian $H_{0}$ ditolak dan $H_{\varpi}$ diterima. Artinya ada perbedaan hasil belajar antara pembelajaran yang menggunakan model pembelajaran TGT dengan media Pop Up dengan model pembelajaran konvensional pada tema 6 subtema 3 pembelajaran 1-3. Sarannya yaitu : 1) Bagi siswa dengan adanya model pembelajaran TGTvariasi dalam pembelajaran. Dengan model pembelajaran TGT siswa lebih senang dan aktif karena dalam pembelajarannya siswa mengalami secara langsung pengalaman belajarnya, 2) Guru dalam pembelajaran dapat menggunakan model pembelajaran TGT dengan media pop up diharapkan mampu meningkatkan hasil belajar dan mampu mencapai hasil belajar yang ditentukan, 3)Sekolah dengan menggunakan model pembelajaran TGT dengan media pop up dalam dunia pendidikan di sekolah agar siswa aktif selama pemebelajaran, 4)Peneliti selanjutnya agar dapat melakukan penelitian model pembelajaran TGT dengan media Pop uptidak hanya tema 6 subtema 3 pembelajaran 1-3 tetapi dalam penelitian tema yang berbeda.

\section{Daftar Pustaka}

Arifin, Zainal. 2013. Evaluasi Pembelajaran. Bandung: PT Remaja Rosdakarya

Arikunto, Suharsimi.2010. Prosedur Penelitian. Jakarta:Rineka Cipta

Arsyad, Azhar. 2011. Media Pembelajaran. Jakarta: PT Raja Grafindo Persada.

Azizah, Nur dkk.Pengaruh Model Tgt Berbantu Media Utama Terhadap Hasil Belajar Matematika Ditinjau Dari AktivitasBelajar Siswa Kelas V SD. E-Jurnal PGSD Universitas PGRI Semarang. Vol .2 No. 4 Tahun 2018.

Daryanto. 2014. Pembelajaran Tematik, Terpadu, Terintegrasi (Kurikulum 2013). Yogyakarta: Gava Media.

Depdiknas. 2013. Undang-Undang RI No. 20 Tahun 2003 tentang Sistem PendidikanNasional. Jakarta : Depdiknas

Elisa Diah. (2018). Pengembangan Media Pembelajaran Pop-Up Book pada Mata Pelajaran IPA Kelas III Sekolah Dasar. Jurnal Jurusan Teknologi Pendidikan.

Fathurrohman, Muhammad. 2017. Model-Model Pembelajaran Inovatif. Jogjakarta: Ar- Ruzz Media.

Hamdani. 2011. Strategi Belajar Mengajar. Bandung: CV Pustaka Setia.

Hergenhahn dan Mattew H Olson. 2008. Theories Of Learning. Jakarta:Prenada Media Group.

Irinto,Agus.2015.Statistik:Konsep Dasar, Aplikasi dan Pengembangan.Edisi Keempat.Jakarta:Kencana

Kadir, Abd dan Asrohah Hanun. 2014. Pembelajaran Tematik. Jakarta: Rajawali Pers.

Khoiriyah Evi. 2018. Pengembangan Media Pembelajaran Pop-Up Book pada Mata Pelajaran IPA Kelas III SDN 3 Junjung Kecamatan Sumbergempol Kabupaten Tulungagung Tahun Ajaran 2017/2018. Jurnal Bidang Pendidikan Dasar (JBPD), Vol.2 No.2 Juni 2018. http: ejournal.unikama.ac.id/index.php/JBPD 
Khotimah, Nurul. 2018. "Keefektifan Model Pembelajran TGT (Teams Games Tournaments) Berbantu Media Mojeko Terhadap Hasil Belajar Siswa Tema Ekosistem Kelas V SDN 3 Banyuringin".Skripsi. FIP, Pend.Guru Sekolah Dasar, Universitas PGRI Semarang.

Kurniawan, Deni. 2014. Pembelajaran Terpadu Tematik. Bandung: Alfabeta.G.

Nur, Melinda Alfiani dkk.Pengembangan Media Pop Up Book Pada Pembelajaran Ips Tentang Kerajaan Dan Peninggalan Sejarah Islam Di Indonesia di Kelas V Sekolah Dasar. EJurnal PGSD Universitas Pendidikan Indonesia. Vol. 4, No. 2 Tahun 2017

Peraturan Pemerintahan Republik Indonesia Nomor 65 Tahun 2013 tentang Perubahan atas Peraturan Pemerintahan Nomor 19 Tahun 2005 tentang Standart Nasional Pendidikan. http: //sindikker.dikti.go.id/. Diakses pada tanggal 23 Oktober 2016

Pramesti, Jatu. 2015. "Pengembangan Media Pop Up Book Tema Peristiwa untuk Kelas III SD Negeri Pakem 1". Jurnal.

Purwanto. 2009. Evaluasi Hasil Belajar. Yogyakarta: Pustaka Pelajar.

Safri Meilia. 2017. Pengembangan Media Belajar Pop-Up Book pada Materi Minyak Bumi. Jurnal Pendidikan Sains Indonesia, Vol. 05, No.01, hlm 107-113, 2017http://jurnal.unsyiah.ac.id/jpsi

Siregar, Eveline dan Hartini Nara. 2014.Teori Belajar dan Pembelajaran. Bogor: Ghalia Indonesia.

Slavin, E Robert.2005. Cooperative Learning. Bandung: Nusa Media.

Soegeng. 2006. Dasar-Dasar Penelitian. Semarang: Ikip PGRI Press

Sudjana. 2005. Metoda Statistika. Bandung: PT. Tarsito.

Sugiyono. 2017. Metode Penelitian Pendidikan. Bandung: Alfabeta.

Suprijono, Agus. 2017. Cooperative Learning. Yogyakarta: Pustaka Pelajar.

Suyono, Hariyanto. 2014. Belajar dan Pembelajaran Teori dan Konsep Dasar. Bandung: PT Remaja Rosdakarya .

Suyono, Hariyanto. 2016. Belajar dan Pembelajaran Teori dan Konsep Dasar. Bandung: PT Remaja Rosdakarya . 